\title{
Chapter 1 \\ Nature-Based Solutions to Climate Change Adaptation in Urban Areas-Linkages Between Science, Policy and Practice
}

\author{
Nadja Kabisch, Horst Korn, Jutta Stadler, and Aletta Bonn
}

\begin{abstract}
Climate change presents one of the greatest challenges to society today. Effects on nature and people are first experienced in cities as cities form microcosms with extreme temperature gradients, and by now, about half of the human population globally lives in urban areas. Climate change has significant impact on ecosystem functioning and well-being of people. Climatic stress leads to a decrease in the distribution of typical native species and influences society through health-related effects and socio-economic impacts by increased numbers of heat waves, droughts and flooding events. In addition to climate change, urbanisation and the accompanying increases in the number and size of cities are impacting ecosystems with a number of interlinked pressures. These pressures include loss and degradation of natural areas, soil sealing and the densification of built-up areas, which pose additional significant challenges to ecosystem functionality, the provision
\end{abstract}

\footnotetext{
N. Kabisch $(\bowtie)$

Department of Ecosystem Services, Helmholtz Centre for Environmental Research - UFZ,

Permoserstraße 15, 04318 Leipzig, Germany

Department of Geography, Humboldt-Universität zu Berlin, Unter den Linden 6, 10099 Berlin, Germany

German Centre for Integrative Biodiversity Research (iDiv) Halle-Jena-Leipzig, Deutscher Platz 5e, 04103 Leipzig, Germany

e-mail: nadja.kabisch@ufz.de; nadja.kabisch@geo.hu-berlin.de

H. Korn • J. Stadler

Federal Agency of Nature Conservation (BfN), Isle of Vilm, Germany

e-mail: horst.korn@bfn.de; jutta.stadler@bfn.de
}
A. Bonn
Department of Ecosystem Services, Helmholtz Centre for Environmental Research - UFZ,
Permoserstraße 15, 04318 Leipzig, Germany
Institute of Ecology, Friedrich Schiller University Jena,
Dornburger Str. 159, 07743 Jena, Germany

German Centre for Integrative Biodiversity Research (iDiv) Halle-Jena-Leipzig,

Deutscher Platz 5e, 04103 Leipzig, Germany

e-mail: aletta.bonn@ufz.de 
of ecosystem services and human well-being in cities around the world. However, nature-based solutions have the potential to counteract these pressures. Nature-based solutions (NBS) can foster and simplify implementation actions in urban landscapes by taking into account the services provided by nature. They include provision of urban green such as parks and street trees that may ameliorate high temperature in cities or regulate air and water flows or the allocation of natural habitat space in floodplains that may buffer impacts of flood events. Architectural solutions for buildings, such as green roofs and wall installations, may reduce temperature and save energy. This book brings together experts from science, policy and practice to provide an overview of our current state of knowledge on the effectiveness and implementation of nature-based solutions and their potential to the provision of ecosystem services, for climate change adaptation and co-benefits in urban areas. Scientific evidence to climate change adaptation is presented, and a further focus is on the potential of nature-based approaches to accelerate urban sustainability transitions and create additional, multiple health and social benefits. The book discusses socio-economic implications in relation to socio-economic equity, fairness and justice considerations when implementing NBS.

Keywords Nature-based solutions - Climate change - Urbanisation - Climate change adaptation $\bullet$ Cities

\subsection{Background}

Climate change presents one of the greatest challenges to society today. Effects on nature and people are first experienced in cities (White et al. 2005) as cities form microcosms with extreme temperature gradients, and by now, about half of the human population globally lives in urban areas (United Nations, Department of Economic and Social Affairs 2014). Already, climate change has significant impact on biodiversity and ecosystem functioning through threatening current habitat conditions due to heat and water stress (European Environment Agency 2012). Climatic stress already leads inter alia to a decrease in the distribution of typical native species and facilitates the establishment of alien invasive species (Knapp et al. 2010). Influences of climate change on society include health-related effects and socioeconomic impacts induced by increased numbers of heat waves, droughts and flooding events (European Environment Agency 2016). In addition to climate change, urbanisation and the accompanying increases in the number and size of cities are impacting ecosystems, as urbanisation is driving a significant conversion of rural to urban landscapes (Seto et al. 2011). A number of interlinked pressures, such as loss and degradation of natural areas, soil sealing and the densification of built-up areas pose additional significant challenges to ecosystem functionality and human well-being in cities around the world. These processes may lead to biodiversity loss (for an overview, see Goddard et al. 2010) and a reduction of functions and services that urban ecosystems provide (Haase et al. 2014). However, urban green and blue 
spaces have the potential to counteract these pressures by providing habitats for a range of species (Niemela 1999; Goddard et al. 2010) and a number of environmental and cultural benefits while contributing to climate change adaptation and mitigation (Kabisch et al. 2015; Kabisch et al. 2016a; see Box 1.1 for definitions).

With regard to urban green and blue spaces, nature-based solutions (NBS) can foster and simplify implementation actions in urban landscapes by taking into account the services provided by nature (Secretariat of the Convention on Biological Diversity 2009). The concept of NBS evolved over the last years and was shaped by several actors (e.g. IUCN and the EU Commission; see Box 1.2 for definition of NBS). The concept of NBS is particularly embedded in the wider discussions on climate change adaptation, ecosystem services and green infrastructure (Kabisch et al. 2016a). Examples of NBS include provision of urban green such as parks and street trees that may ameliorate high temperature in cities (Gill et al. 2007; Bowler et al. 2010) or regulate air and water flows. Allocation of natural habitat space in floodplains may buffer impacts of flood events. Furthermore, architectural solutions for buildings, such as green roofs and wall installations for temperature reduction and related energy savings through reduced cooling loads (Castleton et al. 2010), can contribute to NBS. Importantly, by integrating NBS in urban landscapes, multiple benefits related to climate change adaptation and mitigation are increasingly recognised as influential determinants of human health and well-being (Barton and Grant 2006; Hartig et al. 2014). They relate to the provision and improved availability of urban green spaces and may result in better mental and physical health (Keniger et al. 2013). In addition, NBS may, in many cases, present more efficient and cost-effective solutions than more traditional technical approaches (European Commission 2015). In policy and practice, NBS complement concepts like green infrastructure or ecosystem-based mitigation and adaptation. To date, an increasing number of NBS projects have been implemented. Nevertheless, we are just at the beginning of systematically analysing their (long-term) effects, effectiveness for climate change adaptation and mitigation and provision of co-benefits. Still,

\section{Box 1.1 Definition of Climate Change as well as Mitigation and Adaptation to Climate Change (European Environment Agency 2012)}

Climate change is defined as any change in climate over time, resulting from natural variability or human activity.

Mitigation to climate change refers to anthropogenic interventions to reduce anthropogenic forces of the climate system. Climate change mitigation strategies include those to reduce greenhouse gas emissions and sources and enhancing greenhouse gas sinks.

Adaptation to climate change is defined as the adjustment in natural or human systems such as urban areas in response to actual or expected climatic stimuli or their effects. Climate change adaptation strategies should moderate harm or exploit beneficial opportunities of climate change. 


\section{Box 1.2. Definition of Nature-Based Solutions by IUCN and the European Commission}

IUCN defines nature-based solutions (NBS) as: ‘... actions to protect, sustainably manage and restore natural or modified ecosystems, which address societal challenges (e.g., climate change, food and water security or natural disasters) effectively and adaptively, while simultaneously providing human well-being and biodiversity benefits' (p. xii) (Cohen-Shacham et al. 2016).

The European Commission understands: '... nature-based solutions to societal challenges as solutions that are inspired and supported by nature, which are cost-effective, simultaneously provide environmental, social and economic benefits and help build resilience. Such solutions bring more, and more diverse, nature and natural features and processes into cities, landscapes and seascapes, through locally adapted, resource-efficient and systemic interventions' (European Commission 2016).

knowledge is needed on measuring effectiveness and how the available evidence can be translated into management strategies and policy instruments.

\subsection{Scope of the Book}

This book brings together experts from science, policy and practice to provide an overview of our current state of knowledge on the effectiveness and implementation of NBS and their potential to the provision of ecosystem services, for climate change mitigation and adaptation and co-benefits in urban areas. Scientific evidence to climate change adaptation and mitigation is presented, and a further focus is on the potential of nature-based approaches to accelerate sustainability transitions and to create additional, multiple health and social benefits. The book also discusses socio-economic implications in relation to socio-economic equity, fairness and justice considerations when implementing NBS.

Furthermore, the chapters address tools to embed NBS in practice and policy, e.g. through partnership and community approaches between practice (e.g. urban gardening initiatives including allotment gardens), business and policy. As NBS are multifaceted, the book naturally has a strong interdisciplinary and transdisciplinary scope. The evidence reviewed and presented also feeds into recommendations for creating synergies between ongoing policy processes, scientific programmes and practical implementation of climate change mitigation and adaptation actions in European urban areas.

The book provides the current state of knowledge drawing from interdisciplinary research in urban ecology, urban planning, urban sociology and public health. The book also captures in-depth expertise and experience from policy and practice concerned with urban land development, as well as conservation and enhancement of 
biodiversity and ecosystem services provision. While the focus is on NBS to foster climate change adaptation, the chapters also highlight important multiple cobenefits for human health, quality of life and well-being analysed through interdisciplinary approaches. The book includes papers on new concepts and methods to dealing with the challenges emerging from pressures of climate change and urbanisation - that is, the need for sustainable green space development through NBS at different scales, from single patches to a city wide scale. Many chapters highlight the importance of urban planning on green infrastructure development and biodiversity conservation management within cities and provide pointers to move forward.

Focussing on relevant and up-to-date topics, the contributions of this book relate to the following essential main fields of interdisciplinary socio-environmental science:

1. Theory and management approaches related to nature-based solutions for climate change adaptation

2. Analysis of urban ecosystem services provided through multifunctional urban green spaces

3. Assessment of co-benefits of nature-based solutions to human health and well-being

4. Considerations of environmental justice and social equity related to nature-based solutions implementation

5. Nature-based solutions from a transition theory perspective

6. Municipal governance and socio-economic aspects of implementing naturebased solutions

These topics were intensively discussed at the European conference 'NatureBased Solutions to Climate Change in Urban Areas and Their Rural Surroundings Linkages Between Science, Policy and Practice' that took place in Bonn, Germany, from 17 to 19 November 2015 (Kabisch et al. 2016b). The conference was organised by the German Federal Agency for Nature Conservation (BfN), the Helmholtz Centre for Environmental Research-UFZ, the German Centre for Integrative Biodiversity Research (iDiv) Halle-Jena-Leipzig and the Network of European Nature Conservation Agencies (ENCA).

This book contributes to an increased understanding of how NBS can help to adapt to climate change through the provision of urban ecosystem services, of possibilities and limitations to their performance, and of how urban governance can use this understanding for a successful urban planning in growing cities under global change.

\subsection{Structure and Contents of the Book}

This book is divided into four main parts developing the case for adopting NBS for climate change adaptation. In addition, co-benefits and the implementation challenges of NBS as planning and management tool in urban development are presented. 
1. Part I: Setting the Scene-Climate Change and the Concept of Nature-Based Solutions

2. Part II: Evidence for Nature-Based Solutions to Adapt to Climate Change in Urban Areas

3. Part III: Health and Social Benefits of Nature-Based Solutions in Cities

4. Part IV: Policy, Governance and Planning Implications for Nature-Based Solutions

The various chapters provide up-to-date scientific background information, address policy-related issues and lay out pressing urban land-use planning and management questions. Chapters provide specific examples and applications of NBS in cities with case studies, mainly from Europe but also North American and Chinese settings. Chapters further identify knowledge gaps. Their content is presented below.

\subsubsection{Part I: Setting the Scene-Climate Change and the Concept of Nature-Based Solutions}

The first part presents an overview of the concept of NBS and places it in the context of other relevant concepts such as green infrastructure, ecosystem-based adaptation (EbA) and ecosystem services in urban areas. The part discusses how different interpretations of the NBS concept result in multiple ways of describing and promoting it by a wide range of interested stakeholders.

To set the scene, Tobias Emilsson and Åsa Ode Sang provide an extended overview on climate change impacts on urban areas in Europe with specific focus on urban heat, energy and flooding. The overview also introduces climate change mitigation and adaptation options through urban green and blue spaces as an NBS in urban areas. Important potential planning aspects are discussed. Stephan Pauleit and co-authors discuss main features of the NBS concept in relation to overlaps and differences with other concepts, such as ecosystem-based adaptation (EbA), urban green infrastructure (UGI) and ecosystem services (ESS), which have all recently gained prominence in academic debates and are increasingly referred to in policy making. With this regard, Erik Andersson and co-authors present the idea of a double insurance value of urban ecosystems, which can be seen as one step towards governance processes that better take into account the complexity of the systems we live in and the multifaceted nature of 'hazards'. Using real-world examples from climate change-induced weather extremes, the authors illustrate that insurance consists of two components: first, functioning ecosystems can insure human societies against external disturbances, and second, these habitats need to be resilient themselves in the face of future disturbances that might affect their functioning. Niki Frantzeskaki and co-authors provide case study evidence that NBS are practices that transition initiatives in cities can put in place in order to intervene in their place 
and change the urban fabric. Focussing on three case study examples, the authors can show that NBS have transformative social impact contributing to social innovation in cities. In particular, the chapter highlights different ways how NBS as practices of transition initiatives in cities can get scaled up and hence contribute to accelerating sustainability initiatives.

\subsubsection{Part II: Evidence for Nature-Based Solutions to Adapt to Climate Change in Urban Areas}

Chapters in the second part of the book discuss the evidence for effectiveness of NBS also in comparison to technology-based solutions. In particular, the significance of biodiversity and its elements in cities and their rural surroundings for the adaptation to climate change and in providing ecosystem services is assessed.

In a first paper, Yaella Depietri and Timon McPhearson refer to the role of urban ecosystems in disaster risk reduction. They underline that evidence of the role of healthy ecosystems in disaster risk reduction is still scarce. By referring to cases in Northern America and in Europe, the authors discuss the role of green, blue and grey infrastructures as well as mixed approaches for climate change adaptation in cities in order to illustrate the different opportunities available for urban areas. In their chapter Vera Enzi and colleagues develop the case for architectural solutions and refer to green roof and wall technologies as part of the urban green infrastructure network and as an integrative NBS strategy to adapt to climate change. In particular, the chapter provides an overview about small-scale regulating ecosystem services as microclimatic benefits and impacts of green roofs and walls to city residents, which can be implemented even in densely settled areas. Using best practice examples, authors further show how ecologically improved green roof and wall systems can contribute to urban biodiversity. How urban green space further provides important regulating ecosystem services is shown by Francesc Baró and Erik Gómez-Baggethun by synthesising existing knowledge and using data of green space assessments carried out in Europe. They highlight in particular the role of NBS regarding global and local climate regulation as well as air quality improvement using the case study city of Barcelona. McKenna Davis and Sandra Naumann introduce sustainable urban drainage systems as an NBS to manage flood risk and to minimise the potential impact of floods on the environment and people. In particular, authors assess if sustainable urban drainage systems (SUDS) are cost-effective and offer long-term drainage alternatives to traditional drainage systems. Dagmar Haase also refers to flooding in urban areas, here highlighting the maintenance of natural urban habitats such as wetlands and riparian forest as an NBS to buffer climate change-induced flooding effects. Dagmar Haase shows the different additional ecosystem services through NBS measures, such as provision of recreation opportunities for urban residents and important habitat for wildlife. 


\subsubsection{Part III: Health and Social Benefits of Nature-Based Solutions in Cities}

The third part of this book deals with the potential provision of multiple benefits when applying NBS to climate change adaptation. In particular, multiple benefits of urban green spaces related to health and social justice for urban residents are critically discussed. In this context, urban gardens are presented as one green infrastructure element that can be maintained by private individuals and provides multiple co-benefits.

Matthias Braubach and co-authors provide a comprehensive overview on the scientific literature of how urban green spaces can affect the health of urban residents and present epidemiological evidence of public health benefits of green spaces. In their review, the authors address three urban health dimensions, namely environmental conditions and related health outcomes, urban equity and vulnerability as well as resilience to extreme climate conditions related to climate change. Complementing the previous chapter, Nadja Kabisch and Matilda Annerstedt van den Bosch show how residents' health is linked to urban green space availability and discuss this in light of environmental justice concerns using the case study of Berlin, Germany. The link between the social effects, environmental justice and green implementation projects as NBS in cities is further critically discussed by Annegret Haase. In particular, potential weaknesses of NBS related to social inclusion and cohesion are explained, and the need to fully consider potential drawbacks and repercussions of the implementation and development of urban NBS particularly for lower-income communities is discussed. Using one particular component of the urban green infrastructure network, Ines Cabral and co-authors explore the contribution of allotments and community gardens as multifunctional NBS to achieve societal as well as environmental goals, using the case studies of Lisbon (Portugal), Leipzig (Germany), Manchester(UK) and Poznan (Poland). Furthermore, ecosystem services provided by allotment gardens are identified and analysed.

\subsubsection{Part IV: Policy, Governance and Planning Implications for Nature-Based Solutions}

The last part focusses on policy, governance and planning implications of NBS. In particular, good practice examples of efficient and successful governance approaches are shown, and new actor-networks created by NBS are discussed. This part also shows how NBS might be assessed economically and how economic valuation and related aspects may provide justification to the introduction of NBS in cities. In addition, the chapters in this part discuss new tools and instruments to invest in working with nature for people, to empower people and to encourage multi sectoral partnerships. 
Reflecting on institutional aspects and challenges of the implementation of NBS projects, Chantal van Ham and Helen Klimmek highlight the need for increased and improved collaboration between sectors and stakeholders as well as for a sound evidence base of the economic, social and environmental benefits of NBS in order to foster increasing uptake of NBS in urban areas. The authors analyse current policies and practices for implementing NBS and highlight those which used unconventional but creative partnerships between policymakers, the private sector and civil society, which resulted in innovative and financeable NBS. The chapter draws from international examples of NBS implementation projects and reports and summarises successes as well as tensions presented in these pioneering solution partnerships. Christine Wamsler and co-authors introduce the concept of mainstreaming climate change adaptation to foster sustainable urban development and resilience, in particular mainstreaming ecosystem- or nature-based solutions into urban governance and planning. They also address challenges of NBS implementation through urban governance. In this approach adaptation mainstreaming is considered as the inclusion of climate risk considerations in sector policies and practices. Authors introduce an integrated framework that illustrates potential mainstreaming measures and strategies at different levels of governance by using case studies from Germany and Portugal. The spread of implementation of NBS as driver for innovation in a country with a transition background is discussed by Jakub Kronenberg and co-authors at the case of Poland. They analysed different groups of stakeholders using different example implementation projects across the country. The last chapter in this part refers to socio-economic and financial aspects of NBS implementation projects. Nils Droste and co-authors highlight the difficulties of resource allocation to NBS implementation as municipal revenues are mostly dedicated to single policy goals and predefined sectorial purposes, thereby leaving little room for cross-sectoral investments such as NBS. The authors identify policy instruments with the potential to foster NBS as well as difficulties in leveraging finance to implement NBS.

The book is complemented with a conclusion chapter by the editors. The editors summarise the main challenges for research, urban governance and management described in the chapters and highlight opportunities for future developments, thus leading to overall recommendations for NBS implementation.

We hope this book provides important pointers to the flourishing debate on NBS in urban environments and illustrates good practice with demonstration case studies, so it can fuel further advances in science, policy and practice. Many of the themes have applications beyond urban system with a focus on solutions for sustainable management and conservation in a changing world.

Acknowledgements We thank the external reviewers for providing critical and helpful comments on earlier versions of this chapter and on the book proposal. This work was supported by the German Federal Agency for Nature Conservation (BfN) with funds of the German Federal Ministry for the Environment, Nature Conservation, Building and Nuclear Safety (BMUB) through the research project 'Conferences on Climate Change and Biodiversity' (BIOCLIM, project duration from 2014 to 2017, funding code: 351480 020A). 


\section{References}

Barton H, Grant M (2006) A health map for the local human habitat. J R Soc Promot Heal 126:252-253. doi:10.1177/1466424006070466

Bowler DE, Buyung-Ali L, Knight TM, Pullin AS (2010) Urban greening to cool towns and cities: a systematic review of the empirical evidence. Landsc Urban Plan 97:147-155. doi:10.1016/j. landurbplan.2010.05.006

Castleton HF, Stovin V, Beck SBM, Davison JB (2010) Green roofs; building energy savings and the potential for retrofit. Energ Buildings 42:1582-1591. doi:10.1016/j.enbuild.2010.05.004

Cohen-Shacham E, Walters G, Janzen C, Maginnis S (2016) Nature-based solutions to address societal challenges. Gland, Switzerland

European Commission (2015) Towards an EU research and innovation policy agenda for naturebased solutions \& re-naturing cities. Final Report of the Horizon 2020 Expert Group on NatureBased Solutions and Re-Naturing Cities

European Commission (2016) Policy topics: nature-based solutions. https://ec.europa.eu/research/ environment/index.cfm?pg=nbs. Accessed 11 Sept 2016

European Environment Agency (2012) Climate change, impacts and vulnerability in Europe 2012. An indicator-based report

European Environment Agency (2016) Building resilient cities key to tackling effects of climate change. Copenhagen, Denmark

Gill SE, Handley JF, Ennos AR, Pauleit S (2007) Adapting cities for climate change: the role of the green infrastructure. Built Environ 33:115-133

Goddard M, Dougill AJ, Benton TG (2010) Scaling up from gardens: biodiversity conservation in urban environments. Trends Ecol Evol 25:90-98. doi:10.1016/j.tree.2009.07.016

Haase D, Larondelle N, Andersson E, Artmann M, Borgström S, Breuste J, Gomez-Baggethun E, Gren A, Hamstead Z, Hansen R, Kabisch N, Kremer P, Langemeyer J, Rall EL, McPhearson T, Pauleit S, Qureshi S, Schwarz N, Voigt A, Wurster D, Elmqvist T (2014) A quantitative review of urban ecosystem service assessments: concepts, models, and implementation. Ambio 43:413-433. doi:10.1007/s13280-014-0504-0

Hartig T, Mitchell R, de Vries S, Frumkin H (2014) Nature and health. Annu Rev Public Health 35:207-228. doi:10.1146/annurev-publhealth-032013-182443

Kabisch N, Qureshi S, Haase D (2015) Human-environment interactions in urban green spaces - a systematic review of contemporary issues and prospects for future research. Environ Impact Assess Rev 50:25-34. doi:10.1016/j.eiar.2014.08.007

Kabisch N, Frantzeskaki N, Pauleit S, Naumann S, Davis M, Artmann M, Haase D, Knapp S, Korn H, Stadler J, Zaunberger K, Bonn A (2016a) Nature-based solutions to climate change mitigation and adaptation in urban areas: perspectives on indicators, knowledge gaps, barriers, and opportunities for action. Ecol Soc 21:art39. doi:10.5751/ES-08373-210239

Kabisch N, Stadler J, Korn H, Duffield S, Bonn A (2016b) Proceedings of the European conference on nature-based solutions to climate change in urban areas and their rural surroundings. BfNSkripten. German Federal Agency of Conservation, Bonn

Keniger L, Gaston K, Irvine K, Fuller R (2013) What are the benefits of interacting with nature? Int J Environ Res Public Health 10:913-935. doi:10.3390/ijerph10030913

Knapp S, Kuehn I, Stolle J, Klotz S (2010) Changes in the functional composition of a Central European urban flora over three centuries. Perspect Plant Ecol Evol Syst 12:235-244

Niemela J (1999) Ecology and urban planning. Biodivers Conserv 8:119-131

Secretariat of the Convention on Biological Diversity (2009) Connecting biodiversity and climate change mitigation and adaptation: report of the second Ad Hoc technical expert group on biodiversity and climate change, Montreal

Seto KC, Fragkias M, Güneralp B, Reilly MK (2011) A meta-analysis of global urban land expansion. PLoS One 6:1-9. doi:10.1371/Citation 
United Nations, Department of Economic and Social Affairs PD (2014) World urbanization prospects: the 2014 revision, Highlights (ST/ESA/SER.A/352)

White P, Pelling M, Sen K, Seddon D, Russel S, Few R (2005) Disaster risk reduction: a development concern. A scoping study on links between disaster risk reduction, poverty and development. London, Glasgow

Open Access This chapter is licensed under the terms of the Creative Commons Attribution 4.0 International License (http://creativecommons.org/licenses/by/4.0/), which permits use, sharing, adaptation, distribution and reproduction in any medium or format, as long as you give appropriate credit to the original author(s) and the source, provide a link to the Creative Commons license and indicate if changes were made.

The images or other third party material in this chapter are included in the chapter's Creative Commons license, unless indicated otherwise in a credit line to the material. If material is not included in the chapter's Creative Commons license and your intended use is not permitted by statutory regulation or exceeds the permitted use, you will need to obtain permission directly from the copyright holder. 